\title{
Heterogeneous advanced photo-fenton oxidation of phenolic aqueous solutions over iron-containing SBA-15 catalyst
}

\author{
Z. Bailiche ${ }^{1,2,3, a}$, L. Cherif ${ }^{1}$, S. Royer ${ }^{4}$, A. Bengueddach ${ }^{5}$, S. Fourmentin ${ }^{2,3}$ and S. Siffert ${ }^{2,3}$ \\ ${ }^{1}$ Laboratoire de Catalyse et Synthèse en Chimie Organique, Université de Tlemcen, Algérie \\ 2 Université Lille Nord de France, 59000 Lille, France \\ ${ }^{3}$ ULCO, UCEIV, 59140 Dunkerque, France \\ ${ }^{4}$ Institut de Chimie des Milieux et Matériaux de Poitiers IC2MP, Poitiers, France \\ ${ }^{5}$ Laboratoire de chimie des matériaux Université d'Oran, Algérie
}

\begin{abstract}
Iron-containing SBA15 catalysts have been prepared following different synthesisroutes, direct synthesis by adjusting $\mathrm{pH}$ at 3 and 6 and with post synthesis procedure. Activity and stability of these materials were assessed on the photo-Fenton degradation of phenolic aqueous solutions by $\mathrm{H}_{2} \mathrm{O}_{2}$ using near UV irradiation $(254 \mathrm{~nm})$ at room temperature and initial neutral $\mathrm{pH}$. Their catalytic performance was mentioned in terms of phenol and total organic carbon (TOC) conversions. Several complementary techniques, including XRD, Nitrogen sorption isotherms, UV visible, were used to evaluate the final structural and textural properties of calcined Fe-SBA15 materials. These materials show a high activity and stability of iron species.
\end{abstract}

\section{INTRODUCTION}

Aromatic compounds are common pollutants in the effluents of several industries. The degradation of these pollutants in wastewater streams has emerged as an important concern during last decade. Advanced oxidation processes (AOPs) such as ozonation, photocatalysis, Fenton and a combination of photo-Fenton, $\mathrm{UV} / \mathrm{O}_{3}$, $\mathrm{UV} / \mathrm{H}_{2} \mathrm{O}_{2}$ have received considerable attention as wastewater treatment processes due to their ability to degrade, and in many cases, mineralize various organic compounds that are otherwise resistant to conventional biological and chemical treatments.

The oxidation system based on the Fenton's reagent (hydrogen peroxide in the presence of ferric ions) has been used as a powerful source of oxidative radicals [1]:

$$
\begin{gathered}
\mathrm{Fe}^{3+}+\mathrm{H}_{2} \mathrm{O}_{2} \leftrightarrow \mathrm{Fe}(\mathrm{OOH})^{2+}+\mathrm{H}^{+} \\
\mathrm{Fe}(\mathrm{OOH})^{2+} \rightarrow \mathrm{Fe}^{2+}+\mathrm{HOO}^{\bullet} \\
\mathrm{Fe}^{2+}+\mathrm{H}_{2} \mathrm{O}_{2} \rightarrow \mathrm{Fe}^{3+}+\mathrm{HO}^{-}+\mathrm{HO}^{\bullet} \\
\mathrm{Fe}^{3+}+\mathrm{HOO}^{\bullet} \rightarrow \mathrm{Fe}^{2+}+\mathrm{H}^{+}+\mathrm{O}_{2} .
\end{gathered}
$$

Fenton processes has been shown to be enhanced by light due to the decomposition of the photoactive $\mathrm{Fe}(\mathrm{OH})^{2+}$ species, promoting an additional generation of $\mathrm{OH}$ radicals in solution [2]:

$$
\mathrm{Fe}(\mathrm{OH})^{2+}+\mathrm{h} v \rightarrow \mathrm{Fe}^{2+}+\mathrm{HO}^{\bullet} .
$$

However, in order to overcome some drawbacks of this process (acidic $\mathrm{pH}$ requirement: $\mathrm{pH}=2-4$ ), loss of Fe ions in water, etc., heterogeneous Fenton type systems have been synthesized to catalyse various organic compounds in mild reaction conditions.

a e-mail: bz3946@yahoo.fr
The unique characteristics of mesoporous molecular sieves, such as high surface area, large pore volume and well defined pore size, make the material potential in catalysis, adsorption, etc.

However, few investigations have been reported in using mesoporous materials for heterogeneous Fenton oxidation [3-6]. The purpose of this study is the assessment of Fe-containing SBA-15 mesostructured materials prepared by direct synthesis (by adjusting the $\mathrm{pH}$ at 6 and 3) and post synthesis procedures for the heterogeneous photo-Fenton degradation of phenolic aqueous solutions. Activity and stability of these materials have been evaluated according to the $\mathrm{Si} / \mathrm{Fe}$ ratio 20 and 60 .

\section{EXPERIMENTAL}

A detailed synthesis procedure for mesoporous silica SBA-15 has been reported elsewhere [7]. Iron substituted mesoporous SBA15 molecular sieve has been prepared by direct synthesis at $\mathrm{pH}=3$ and 6 and post synthesis procedures using iron nitrate as source of iron.

Direct synthesis: Fe-SBA- 15 materials synthesized at $\mathrm{pH}$ 3 were prepared as follows: $4.0 \mathrm{~g}$ triblock copolymer poly (propylene oxide)-poly (ethylene oxide) (EO20PO70EO20 Pluronic 123 from Aldrich) was dissolved in $30.0 \mathrm{~g}$ of water and stirred for $4 \mathrm{~h}$ at $40^{\circ} \mathrm{C} .9 .0 \mathrm{~g}$ of orthosilicate (TEOS) and the appropriate amount of iron nitrate were added directly to the homogeneous solution $(\mathrm{Si} / \mathrm{Fe}=20$ and 60). Then appropriate quantity of $0.3 \mathrm{M} \mathrm{HCl}$ was added to adjust the $\mathrm{pH}$ value of mixture at 3 .

The gel was stirred for $24 \mathrm{~h}$ and then maintained at $100^{\circ} \mathrm{C}$ in a Teflon-lined autoclave for another $48 \mathrm{~h}$. The resultant precipitate was collected, washed thoroughly with distilled water; template removal was achieved by calcination in air at $500^{\circ} \mathrm{C}$ for $4 \mathrm{~h}$ (heating rate: $1{ }^{\circ} \mathrm{C} / \mathrm{mn}$ ).

Fe-SBA-15 materials synthesized at $\mathrm{pH}$ 6: $4.0 \mathrm{~g}$ triblock copolymer poly (propylene oxide) -poly (ethylene 
Table 1. Physical properties of the calcined FeSBA15.

\begin{tabular}{|l|c|c|c|c|c|c|c|}
\hline Sample & SBA-15 & \multicolumn{2}{|c|}{ Fe/SBA-15 } & \multicolumn{2}{c|}{ Fe-SBA-15 pH6 } & \multicolumn{2}{c|}{ Fe-SBA-15 pH3 } \\
\hline $\mathrm{Si} / \mathrm{Fe}$ & $/$ & 20 & 60 & 20 & 60 & 20 & 60 \\
\hline $\mathrm{d}_{100}(\AA)$ & 96 & 103.8 & 101.4 & 91.9 & 101.5 & 92.3 & 103.7 \\
\hline $\mathrm{a}(\AA)$ & 110.8 & 119.9 & 117.1 & 106.1 & 117.2 & 106.6 & 119.7 \\
\hline
\end{tabular}

oxide) $\left(\mathrm{EO}_{20} \mathrm{PO}_{70} \mathrm{EO}_{20}\right.$ Pluronic 123 from Aldrich) was dissolved in $40 \mathrm{ml} 2 \mathrm{M} \mathrm{HCl}$ and stirred for $30 \mathrm{mn}$ at $40^{\circ}$ C. $9.0 \mathrm{~g}$ of orthosilicate (TEOS) was added to the homogeneous solution Then appropriate quantity of $2 \mathrm{M} \mathrm{NH}_{4} \mathrm{OH}$ were added to adjust the $\mathrm{pH}$ value of mixture to 6 , then the appropriate amount of iron nitrate were added directly to the homogeneous solution in order to obtain a well defined $\mathrm{Si} / \mathrm{Fe}=20$ and 60 . The gel was stirred for $2 \mathrm{~h}$ and then maintained at $100{ }^{\circ} \mathrm{C}$ in a Teflon-lined autoclave for three days.

The resultant precipitate was collected, washed thoroughly with distilled water; template removal was achieved by calcination in air at $500^{\circ} \mathrm{C}$ for $4 \mathrm{~h}$ (heating rate: $1{ }^{\circ} \mathrm{C} / \mathrm{mn}$ ). The samples were called Fe-SBA-15 (n) where $\mathrm{n}$ represented the $\mathrm{Si} / \mathrm{Fe}$ ratio.

Post-synthesis: the calcined SBA-15 (0.5 g) was dispersed in $50 \mathrm{ml}$ of deionised water containing various amounts of iron nitrate, in order to obtain a well defined $\mathrm{Si} / \mathrm{Fe}$ ratio equal to 20 and 60 . The resulting mixture was stirred at room temperature for $12 \mathrm{~h}$ and the powder was filtered, washed with deionised water and dried at room temperature in air. The samples were called Fe/SBA-15 (n).

Various techniques including XRD, $\mathrm{N}_{2}$ adsorption and diffuse reflectance UV-Vis (DR-UV-Vis) were employed for the materials characterization.

Heterogeneous photo-Fenton reaction were carried out in a cylindrical pyrex reactors with one central and three peripheral female conical connections for the inflow and outflow of the solution model using phenol as reactant and hydrogen peroxide as oxidant.

The catalyst $(100 \mathrm{mg})$ was put into $100 \mathrm{ml}$ of an aqueous phenol solution $\left(5 \times 10^{-4} \mathrm{~mol} \mathrm{~L}^{-1}\right)$ and the required amount of $\mathrm{H}_{2} \mathrm{O}_{2}$ was used for a complete phenol oxidation.

$$
\mathrm{C}_{6} \mathrm{H}_{6} \mathrm{O}+14 \mathrm{H}_{2} \mathrm{O} \rightarrow 6 \mathrm{CO}_{2}+17 \mathrm{H}_{2} \mathrm{O} \text {. }
$$

The reaction was carried out in ambient conditions (atmospheric pressure, $25^{\circ} \mathrm{C}$ and at neutral $\mathrm{pH}$ ).

A dark Fenton were performed in atmospheric pressure, $25^{\circ} \mathrm{C}$ and the $\mathrm{pH}$ of the reaction was maintained at 3 .

Phenol conversions were determined by High performance liquid chromatograph (HPLC, Waters 600) equipped with a $\mathrm{C}-18$ column at a rate of $1 \mathrm{ml} / \mathrm{min}$ with UV detection with amobile phase of $20 \%$ acetonitrile and $80 \% \mathrm{H}_{2} \mathrm{O}$.

Iron leaching was systematically evaluated by ICP analyses model (820 MS Varian) after catalytic tests.

Totalorganic carbon (TOC) content of the solutions after reaction was analyzed using a Shimadzu TOC-VCSH analyzer.

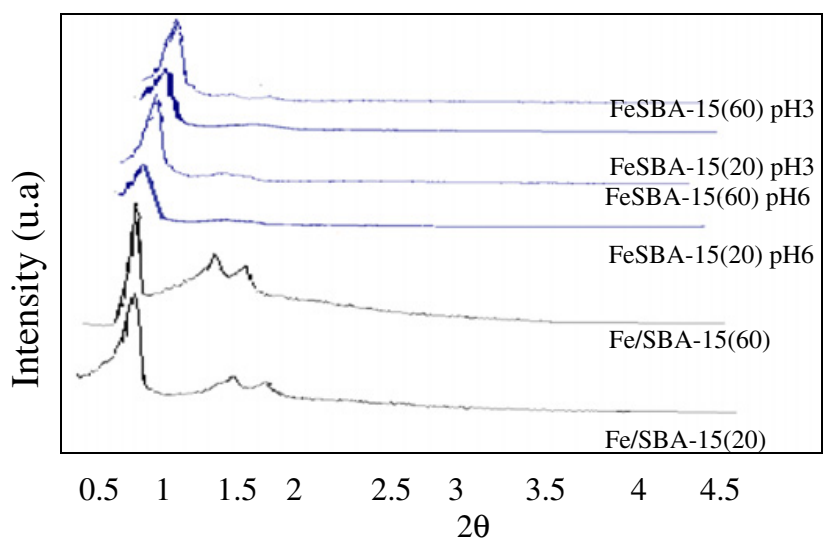

Figure 1. XRD profiles of FeSBA15.

\section{RESULTS AND DISCUSSION}

Small angle $X$ ray diffraction patterns of the Ironcontaining SBA-15 materials are shown in Fig. 1. These materials exhibit a low angle reflections indexed as (100), (110) and (200) which can be associated with the hexagonal symmetry characteristic of mesoporous SBA-15. We can note that co-condensed materials (Fe-SBA-15) are not as highly ordered as impregnated materials Fe-SBA-15. The XRD patterns of Fe-SBA-15 show that the peaks (110) and (200) are not well resolved whatever the synthesis $\mathrm{pH}$ value and $\mathrm{Si} / \mathrm{Fe}$ ratio. This could be explained by the lattice distortion after insertion of $\mathrm{Fe}$. Since the radius of the ionic $\mathrm{Fe}^{3+}\left(\mathrm{r}_{\mathrm{Fe}}^{3+}=0.63 \AA\right)$ is larger than that of $\mathrm{Si}^{4+}\left(\mathrm{r}_{\mathrm{Si}}^{4+}=\right.$ $0.40 \AA)$, the increase in the unit cell parameter value of the Fe-SBA-15 (60) material (Table 1) may indicate that $\mathrm{Fe}^{3+}$ ions are incorporated into the frame work of the SBA-15 material; generally, it is expected that the unit cell parameter will be enlarged after the incorporation of metal cations with ionic radius larger than that of $\mathrm{Si}^{4+}$. However the Fe rich containing SBA15 (Fe-SBA-15 (20)) presents a decrease in its unit cell parameter; this result could be attributed to a partial collapse of hexagonal porosity caused by the modification induced by the iron introduction in the mesoporous silica structure $[8,9]$.

In all cases, the absence of diffraction peaks at $2 \theta>$ $10^{\circ}$ seems to exclude the presence of $\mathrm{Fe}_{2} \mathrm{O}_{3}$ crystallites or in too low quantity tobe observed.

Typical irreversible type IV adsorption isotherms as defined by IUPAC [10] were observed which is typical of mesoporous materials. The $\mathrm{N}_{2}$ isotherms remained unchanged in shape for impregnated materials $\mathrm{Fe} / \mathrm{SBA} 15$ and co-condensed materials (Fe-SBA15) at $\mathrm{pH}=6$ compared to that of SBA15. By contrast, the $\mathrm{N}_{2}$ isotherms were less sharp for co-condensed materials 
Table 2. Specific surfaces of FeSBA-15 compounds.

\begin{tabular}{|l|l|l|l|l|l|l|}
\hline Sample & \multicolumn{2}{|l|}{ Fe/SBA-15 } & \multicolumn{2}{l|}{ Fe-SBA-15pH6 } & \multicolumn{2}{l|}{ Fe-SBA-15pH3 } \\
\hline $\mathrm{Si} / \mathrm{Fe}$ & 20 & 60 & 20 & 60 & 20 & 60 \\
\hline $\mathrm{S}_{\mathrm{BET}}\left(\mathrm{m}^{2} / \mathrm{g}\right)$ & 732 & 601 & 822 & 623 & 502 & 895 \\
\hline
\end{tabular}

Table 3. Activity of catalysts FeSBA-15.

\begin{tabular}{|c|c|c|c|c|}
\hline Sample & $\mathrm{t}$ (min) & $\mathbf{X}_{\text {Phenol }}(\%)$ & Leaching ${ }^{\text {a } \%}$ & $\mathbf{X}_{\text {TOC }}(\%)$ \\
\hline \multirow{4}{*}{ Fe/SBA-15 (20) } & 0 & 0 & \multirow{4}{*}{33.3} & \multirow{4}{*}{13.3} \\
\hline & 5 & 93.9 & & \\
\hline & 10 & 98.7 & & \\
\hline & 15 & 100 & & \\
\hline \multirow{4}{*}{ Fe/SBA-15 (60) } & 0 & 0 & \multirow{4}{*}{11.8} & \multirow{4}{*}{16.3} \\
\hline & 5 & 84.0 & & \\
\hline & 10 & 96.2 & & \\
\hline & 15 & 100 & & \\
\hline \multirow{4}{*}{ Fe-SBA-15 (20) pH6 } & 0 & 0 & \multirow{4}{*}{22.5} & \multirow{4}{*}{5.3} \\
\hline & 5 & 90.5 & & \\
\hline & 10 & 100 & & \\
\hline & 15 & 100 & & \\
\hline \multirow{4}{*}{ Fe-SBA-15 (60) pH6 } & 0 & 0 & \multirow{4}{*}{15.9} & \multirow{4}{*}{7.3} \\
\hline & 5 & 90.0 & & \\
\hline & 10 & 100 & & \\
\hline & 15 & 100 & & \\
\hline \multirow{4}{*}{ Fe-SBA-15 (20) pH3 } & 0 & 0 & \multirow{4}{*}{17.0} & \multirow{4}{*}{11.4} \\
\hline & 5 & 90.7 & & \\
\hline & 10 & 100 & & \\
\hline & 15 & 100 & & \\
\hline \multirow{4}{*}{ Fe-SBA-15 (60) pH3 } & 0 & 0 & \multirow{4}{*}{15.0} & \multirow{4}{*}{9.6} \\
\hline & 5 & 79.2 & & \\
\hline & 10 & 96.7 & & \\
\hline & 15 & 100 & & \\
\hline
\end{tabular}

a: Percentage from leaching iron leached from the catalyst.

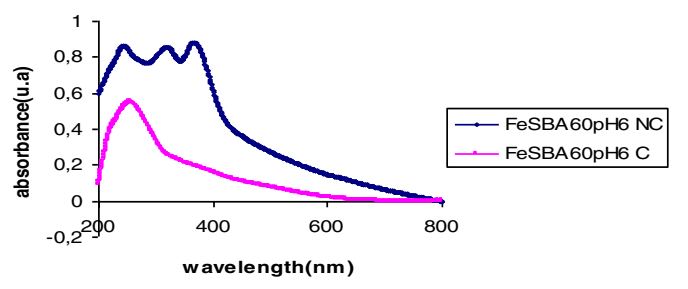

Figure 2. The diffuse reflectance UV-visible spectra of FeSBA15.

(Fe-SBA15) at $\mathrm{pH}=3$ indicating that the materials were less ordered and uniform compared to SBA15.

The BET surface area values of FeSBA-15 materials are listed in Table 2. SBA-15 sample exhibits a specific surface area of $930 \mathrm{~m}^{2} / \mathrm{g}$. A decrease in specific surface area is logically observed after iron incorporation [5].

Diffuse reflectance UV-vis spectroscopy was used to investigate the nature the Fe (III) species. The DR-UV-vis spectra of as synthesised and calcined FeSBA15 samples are shown in Figure 2.

The spectra of as synthesised Fe-SBA15 ( $\mathrm{Si} / \mathrm{Fe}=$ 20 and 60) synthesized at $\mathrm{pH}=6$ show two absorption bands below $250 \mathrm{~nm}(210 \mathrm{~nm}, 240 \mathrm{~nm})$, two bands between 300 and $400 \mathrm{~nm}$. The bands below $250 \mathrm{~nm}$ are attributed to isolated $\mathrm{Fe}^{3+}$ in tetrahedral coordination and those between 300 and $400 \mathrm{~nm}$ are attributed to iron oxide nanoclusters $\left(\mathrm{Fe}_{x} \mathrm{O}_{y}\right)$ [11]. Both samples are free of large $\mathrm{Fe}_{2} \mathrm{O}_{3}$ as evidenced by missing bands above $400 \mathrm{~nm}$.

The DR-UV-Vis spectra of calcined Fe-SBA-15 samples synthesized at $\mathrm{pH}=6$ show the exaltation of the band attributed to $\mathrm{Fe}^{3+}$ in tetrahedral coordination $(<250 \mathrm{~nm})$, disappearance of bands attributed to nanoclusters of iron oxide $(300-400 \mathrm{~nm})$ and the appearance of a band at $250 \mathrm{~nm}(<300 \mathrm{~nm})$ attributed to $\mathrm{Fe}^{3+}$ in octahedral coordination. This result canbe explained by the redispersion of the iron species and their partial insertion intothe frame work after calcination of the $\mathrm{Fe}$ SBA-15 materials. The insertion of iron into the framework after calcination is in contradiction with what is usually observed with mesoporous materials exchanged by metal.

The spectra of as synthesised and calcined Fe-SBA-15 $(\mathrm{Si} / \mathrm{Fe}=20)$ synthesized at $\mathrm{pH}=3$ show two absorption bands; the first is attributed to $\mathrm{Fe}^{3+}$ in tetrahedral coordination $(<250 \mathrm{~nm})$ and the second is attributed to nanoclusters of iron oxide $(300-400 \mathrm{~nm})$.

\section{Activity and stability of catalytic systems in photoas-} sisted oxidation of phenolic aqueous solutions

Table 3 summarizes the activity of all the catalysts prepared during this study in the photo-Fenton of phenol 
degradation at different reaction times. A nearly total phenol removal is displayed by all samples after reaction times of $10 \mathrm{~min}$. Table 3 shows the effect of $\mathrm{Si} / \mathrm{Fe}$ ration and the synthesis procedure of FeSBA-15 on phenol degradation, suggesting in the case of Fe-SBA15 synthesized at $\mathrm{pH} 3$ that the decrease in $\mathrm{Si} / \mathrm{Fe}$ from 60 to 20 accelerate the oxidation of phenol since more radicals are produced from higher iron loaded catalysts according to the Eqs. (1-4). However, in the case of FeSBA-15 synthesized at pH6 and Fe/SBA-15 synthesized by post-synthesis procedure, the oxidation of phenol is not accelerated with the decrease in $\mathrm{Si} / \mathrm{Fe}$ from 60 to 20; Therefore $\mathrm{Si} / \mathrm{Fe}=60$ is the optimum value and $100 \%$ of phenol has been degraded after reaction time of $10 \mathrm{~min}$ with Fe-SBA-15 synthesized at pH6. It has been demonstrated that the photo-Fenton activity of a catalyst can be influenced by its surface area, crystal structure, particle size distribution or surface hydroxyl group density [12].

If we compare the values of TOC conversion we observed a high activity for the catalyst Fe-SBA-15 synthesized at $\mathrm{pH} 6$.

An important point in the design of heterogeneous catalytic systems for advanced oxidation processes is the resistance of metal species to be leached into the aqueous solution under the oxidant; in this sense, stability of all the materials was evaluated in the terms of the percentage of iron leached from the catalyst with the reaction time. The catalyst Fe/SBA-15 (20), synthesized by post-synthesis procedure, shows a higher leaching degree in comparison to those obtained by direct synthesis, which are mainly composed of framework iron which is more resistant to be leaching out into the aqueous solution.

\section{Study of parallel reactions on thephenol photo- degradation}

The influence of parallel reactions such as dark-Fenton, degradation mediated by photolysis of $\mathrm{H}_{2} \mathrm{O}_{2}$ and adsorption phenomenon on the overall degradation of phenol has been studied. The results show that mineralization of phenol towards carbon dioxide and water by irradiated homogeneous Fenton catalytic systems and $\mathrm{UV} / \mathrm{H}_{2} \mathrm{O}_{2}$ processes may occur along with heterogeneously Fenton photo-assisted reactions, but the remarkable contribution of iron containing SBA-15 catalyst is undoubtedly demonstrated.

\section{Study of stability of catalysis}

The performance of Fe-SBA-15 (60) synthesized at pH6 in phenol degradation after catalyst recycling with filtration and water washing is similar to the first test; this suggests the stable performance of Fe-SBA-15 (60) in heterogeneous Fenton oxidation.

\section{CONCLUSION}

A series of iron-based mesoporous materials were prepared following different routes. Fe-SBA15 prepared by direct synthesis are not as highly ordered as impregnated materials Fe/SBA-15. It's worth noting that after calcination of Fe-SBA-15 synthesized at pH6, the extra framework iron species are redispersed and partially inserted into the framework. Activity and stability of FeSBA-15 for treatment of phenolic aqueous solutions depend on the synthesis strategy and $\mathrm{Si} / \mathrm{Fe}$ ratio.

Fe-SBA-15 (60) synthesized at pH6 is a promising catalyst for photo-Fenton processes.

The authors are grateful to PHC Maghreb n ${ }^{\circ} 27959$ PD for financial support.

\section{References}

[1] C. Walling, A. Goosen, J. Am. Chem. Soc. 95, 29872991, 1973.

[2] V. Nadtochenco, J. Kiwi, Inorg. Chem. 37, 52335238, 1998.

[3] N. Gokulakrishnan, A. Pandurangan, P. K. Sinha, J. Chem. Tech. Biot., 82, 25-32, 2007.

[4] F. Martinez, G. Calleja, J. A. Melero, R. Molina, Applied Catal. B: Environmental, 60, 181-190, 2005.

[5] L. Xiang, S. Royer, H. Zhang, J. -M. Tatibouët, J. Barrault, S. Valange, J. Hazard. Mater., 172, 11751184, 2009.

[6] P. Shukla, S. Wang, H. Sun, H. M. Ang, M. Tadé, Chem. Eng. J., 164, 255-260, 2010.

[7] D. Zhao, J. Feng, Q. Huo, N. Melosh, G.H. Frederickson, B.F. Chmelka, G. D. Stucky, Science, 279, 548, 1998.

[8] Z. EL Berrichi, L. Cherif, O. Orsen, J. Fraissard, J.P. Tessonnier, E. Vanhaecke, B. Louis, M.J. Ledoux, C. Pham-Huu, Appl. Catal. A, 298, 194, 2006.

[9] C.F. Cheng. M.D. Albo, J. Klouski. Chem. Phys. Lett., 250, 328, 1996.

[10] IUPAC Manual of Symbols and Terminologie, Appendix 2, Part 1 Colloid andSurface Chemistry, Pure. Appl. Chem, 1972, 31, 578.

[11] S. Bordiga, R. Buzzoni, F. Geobaldo, C. Lamberti, E. Giamello, A. Zecchina, G. Petrini, G. Tozzola, G. Vlaic, J. Catal., 158, 486, 1996.

[12] D.W. Bahnemann, in: E. Pelizzetti, M. Schiavello (Eds. ), Kluwer Academic Publishers, Dordrecht, p. $251,1991$. 